\title{
Association between electronic health record use and quality of care in high Medicaid nursing homes
}

\author{
Ganisher Davlyatov $^{1} \wedge$, Justin Lord $^{2} \wedge$, Akbar Ghiasi ${ }^{3}$, Robert Weech-Maldonado $^{4} \wedge$ \\ ${ }^{1}$ Department of Health Administration and Policy, Hudson School of Public Health, University of Oklahoma Health Sciences Center, Oklahoma \\ City, OK, USA; ${ }^{2}$ Department of Health Administration, College of Business, Louisiana State University, Shreveport, LA, USA; ${ }^{3}$ Department of \\ Health Administration, H-E-B School of Business and Administration, University of the Incarnate Word, San Antonio, TX, USA; ${ }^{4}$ Department of \\ Health Services Administration, School of Health Professions, University of Alabama at Birmingham, Birmingham, AL, USA \\ Contributions: (I) Conception and design: R Weech-Maldonado, G Davlyatov, J Lord; (II) Administrative support: R Weech-Maldonado; (III) \\ Provision of study materials or patients: R Weech-Maldonado; (IV) Collection and assembly of data: G Davlyatov, A Ghiasi, J Lord; (V) Data analysis \\ and interpretation: G Davlyatov; (VI) Manuscript writing: All authors; (VII) Final approval of manuscript: All authors. \\ Correspondence to: Ganisher Davlyatov, PhD, MD. Department of Health Administration and Policy, Hudson School of Public Health, University of \\ Oklahoma Health Sciences Center, 801 Northeast 13th Street, Oklahoma City, OK 73126, USA. Email: gdavlyat@ouhsc.edu.
}

Background: Nursing homes operating in resource-constrained environments typically have lower professional staffing and worse quality. Electronic health records (EHRs) have been utilized as an effective tool to improve the quality of care in nursing homes. This study examines the association between EHR use and the quality of care in high Medicaid nursing homes.

Methods: The study used primary and secondary data from Brown University's Long-Term Care Focus, Nursing Home Compare, Area Health Resource File, and Medicare Cost Reports for the years 2017-2018. The primary survey data was collected through a national mailer to Directors of Nursing (DONs) in highMedicaid nursing homes. The dependent variable, nursing home quality, was conceptualized using Nursing Home Compare Five-Star Quality Rating System where the higher score represents better quality (1 to 5). The independent variable, EHR score, was a composite measure developed from 23 items. Ordered logistic regression was used to model the relationship between the average EHR score and the quality star rating in high-Medicaid nursing homes.

Results: There was a significant positive relationship between the average EHR score and the five-star quality rating. For a one unit increase in the average EHR score, the odds of being in a higher star rating category increases by $50 \%$. Additional factors, such as, being a not-for-profit, having higher occupancy rate, and being located in a higher per capita income county were significantly associated with higher quality.

Conclusions: We found that EHR use in high-Medicaid nursing homes was positively associated with improvements in quality. This finding provides additional support to the promising role of EHR in improving quality of care among resource-constrained nursing homes. These under-resourced nursing homes face challenges as it relates to quality, the adoption and use of EHRs may facilitate improvements in quality of care.

Keywords: Electronic health record (EHR); quality of care; nursing home; health disparities

Received: 20 May 2020; Accepted: 06 November 2020; Published: 25 September 2021.

doi: $10.21037 /$ jhmhp-20-64

View this article at: http://dx.doi.org/10.21037/jhmhp-20-64

\footnotetext{
^ ORCID: Ganisher Davlyatov, 0000-0001-9410-9696; Justin Lord, 0000-0002-4557-955X; Robert Weech-Maldonado, 0000-0002-50050909.
} 


\section{Introduction}

The need for long-term care is booming as the projected number of people requiring nursing home care is expected to jump from 1.3 million in 2010 to 2.3 million by 2030 (1). The rapid growth of the aging population has placed an increased burden on the long-term care industry (2). HighMedicaid nursing homes may face even more pressure due to their payer-mix and low level of resources. HighMedicaid nursing homes are described as having a high proportion of Medicaid residents ( $85 \%$ or higher), a lower percentage of private pay residents (10\% or less), and a low percent of residents on Medicare ( $8 \%$ or less) (3). Quality of care is a prevalent issue facing all nursing homes, yet this issue may be worse for high-Medicaid nursing homes as they are often characterized as having lower professional staffing and worse quality (3).

There have been many efforts to address the challenges of delivering high quality care in nursing homes. The use of electronic health records (EHR) may be one effective tool in improving the quality of care in long-term care settings (4). Unlike traditional paper-based documentation, which is often illegible, inconsistent (5), error-prone, and difficult to update (6), EHRs help provide accurate, upto-date, and complete information at the point of care; improve efficiency and productivity; and enable quick access to patient records $(7,8)$. Further, facilities can access and share patient information from different organizations, which improves care coordination and patient safety, while potentially leading to reduced costs (9). However, there are barriers to EHR implementation in nursing homes especially those that are under-resourced.

The adoption and implementation of EHR systems can be costly. Unlike hospitals and ambulatory care providers, nursing homes were excluded from federal incentives, such as the Health Information Technology for Economic and Clinical Health (HITECH) Act that have been instrumental in helping providers secure public funds to offset EHR adoption costs $(10,11)$. As such, EHR adoption rates have been around $65 \%(10)$, while hospitals and ambulatory care providers have EHR adoption rates over $80 \%(12,13)$. Additional barriers to nursing home EHR adoption are the costs associated with EHR training, infrastructure, and maintenance $(14,15)$. Studies have found that the adoption and use of EHR has had a mostly positive effect on the quality of care in nursing facilities $(16,17)$. Despite the benefits attributed to EHRs, nursing homes lag behind other healthcare settings in adoption and use of these systems. Under-resourced nursing homes may be even less likely to adopt EHRs as compared with other facilities with adequate levels of resources. Given the benefits that EHR can have on resident quality, we wanted to explore the adoption and use of EHR as it related to quality of care in under-resourced nursing homes.

\section{Conceptual framework}

Using tenets from Donabedian's Structure-ProcessOutcome (SPO) model and knowledge-based view of the firm, we examine the relationship between the EHR use and quality of care in high-Medicaid nursing homes. Donabedian's SPO model is one of the most widely used frameworks in examining the factors that influence quality of care (18). Structure captures the resources that a nursing home has in place to deliver care. Structural elements have been conceptualized as the presence of EHR, number of nurses per patient, and even leadership styles. Process refers to the activities health care providers utilize to deliver care, such as, the appropriate use of catheters, providing fall-related guidance, and other health related activities. Outcomes are the results of health care provider activities. For example, whether the residents received their flu shots, and/or how many residents fell and so on. EHR implementation and use, is an integral part of the nursing homes structure and has been found to help organizations deliver better care by minimizing errors and improving safety $(16,19)$. This study used the SPO model to examine the relationship among the structure and outcomes, through the use of EHRs in high-Medicaid nursing homes and resident quality outcomes.

According to the knowledge-based view, knowledge is a source of a competitive advantage (20). Knowledge management is defined as the process of creating or locating knowledge and managing the dissemination of knowledge within and between organizations $(21,22)$. EHRs allow for information/knowledge to be collected, communicated, and acted upon more efficiently and effectively. Knowledge managmenet has been conceptualized using three dimensions: knowledge acquisition; knowledge dissemination, and knowledge responsiveness $(23,24)$. Knowledge acquisition pertains to the processes used to locate, create, or discover knowledge. This may also include systems, like an EHR, that helps nursing homes collect and use data. Knowledge dissemination pertains to how knowledge is distributed and applied throughout 
the nursing homes. For example, the accessibility of resident data that an EHR provides can facilitate staff care. Knowledge responsiveness relates to the way the organization utilizes knowledge and includes activities. The responsiveness can be seen as how quickly the organization responds to residents or implement changes based on information/knowledge. Knowledge management processes can improve organizational outcomes and quality because it supports better decision-making (22). EHR use can help nursing homes process, disseminate, and react to knowledge more quickly thus improving quality outcomes, therefore, it is hypothesized:

H1: Greater EHR implementation will have a positive impact on resident care quality in bigh-Medicaid nursing homes.

We present the following article in accordance with the SURGE reporting checklist (available at http://dx.doi. org/10.21037/jhmhp-20-64).

\section{Methods}

\section{Data}

The study used primary and secondary data sources for the years of 2017-2018. The primary survey data was collected through a national mailer to Directors of Nursing (DONs) in high-Medicaid nursing homes. Primary survey data of nursing home administrators was collected through three rounds of mailed and online surveys. A cover letter outlining the purpose of this survey and signed by the Principle Investigator of this project (\#1R01HS023345-01) was sent to all participants. As an incentive for study participation, the respondents of the survey were sent a $\$ 25$ gift card. The first round of surveys was sent to all nursing homes $(n=1,518)$ who had a $85 \%$ or higher Medicaid census. Additional criteria were applied to the sample size that excluded nursing homes with more than $10 \%$ of private pay and greater than $8 \%$ supported by Medicare (3), which led to a sample size of 1,050 . In the end, we had received 391 responses for a response rate of $37 \%$.

Survey data were merged with secondary datasets including Brown University's Long-Term Care Focus (LTCFocus), Nursing Home Compare, and Area Health Resource File. LTCFocus data provides nursing home organizational, demographic, quality, and market information. The Nursing Home Compare data provides quality of resident care and staffing information. The Area Health Resource File provides market and demographic information for the county.

\section{Variables}

The main dependent variable was the five-star quality rating obtained from The Centers for Medicare and Medicaid Services' (CMS) Nursing Home Compare Five-Star Quality Rating System. The Nursing Home Compare website rates nursing homes on a scale between 1 (nursing homes with quality below average) and 5 (nursing homes with quality above average). The five-star quality rating include three sources to determine a nursing home's overall rating: health inspections, staffing, and quality measures. The health inspection rating captures information on standard, as well as, complaint surveys. The staffing rating has information about the number of hours of care provided on average to each resident daily by nursing staff. The quality measures rating has information on nine different clinical measures, such as, number of hospitalizations, number of outpatient emergency department visits, bladder catheter use, antipsychotic medication use, pressure ulcers, urinary tract infection, flu shot, pneumonia vaccine, and changes in resident mobility.

The main independent variable-EHR score-was comprised of 23 items from dimensions of administrative functions, documentation, order entry, results viewing, and clinical tools (Table 1) (25). The administrative functions included administrative processes and reporting such as scheduling systems and clinical task assignments. The documentation included health information and data such as resident demographics and medical history. The order entry had order management information including medication order entry. The results viewing had data to help manage results such as routing, managing, and presenting test results to clinical personnel for review. The clinical tool had decision support system and telemonitoring/telehealth data. Each item had four response options $(0=$ not available, $1=$ paper only, $2=$ paper and electronic, $3=$ fully electronic) (Table 2). The composite score was the average of 23 items.

Control variables included organizational-level (ownership, chain affiliation, size, occupancy rate, Medicare and Medicaid payer mix, use of nurse practitioners/ physician assistants, Acuity Index, and race/ethnicity), and county-level factors (Medicare Managed Care Organization market penetration, per capita income, educational level, unemployment rate, poverty level and competition/ Herfindahl-Hirschman Index (HHI), location, and percent of individuals over 65). Ownership was a categorical variable that identified whether a nursing home was for-profit $(0=$ for-profit), not-for-profit (1= not-for-profit) or government- 
Table 1 Electronic Health Records (EHR) Functionalities and Components

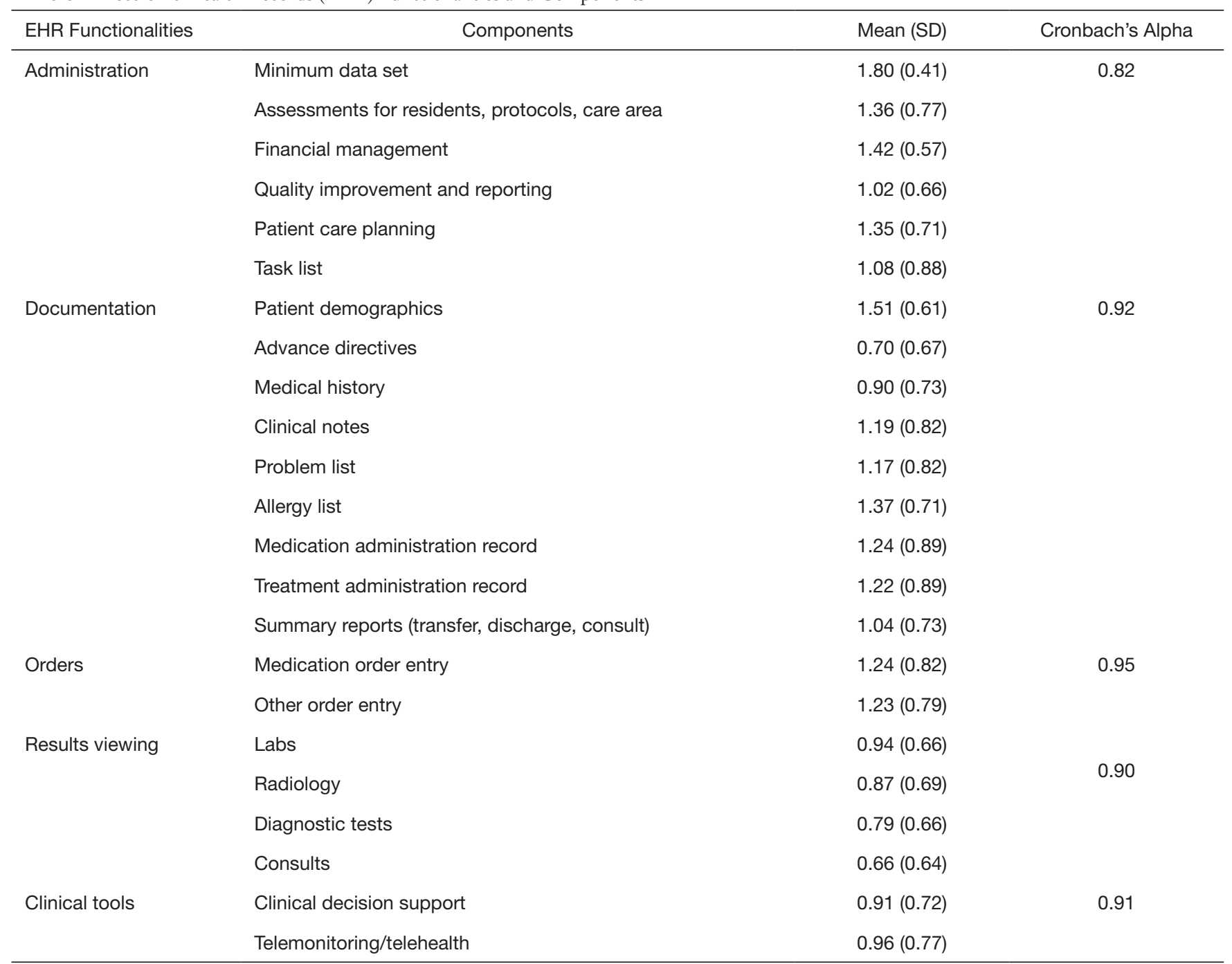

owned $(3=$ government-run). Chain affiliation reflected whether the nursing home was part of a chain $(0=$ freestanding; $1=$ chain affiliated). Size captured the total number of beds within the nursing home. Occupancy rate was the percentage of occupied nursing home beds. Payer mix identified the proportion of the facilities residents who were on Medicaid and Medicare. Presence of nurse practitioners/ physician assistants simply indicated if the facility had a nurse practitioner/physician assistant or not. The Acuity Index was an average measure of the resident's level of care needed. This measure was based on the number of residents needing various levels of assistance with mobility, activities of daily living (ADL), special treatments, as well as, the proportion of residents that are bedfast, exhibit dementia, and who require assistance with ambulation or transfers. Race/ethnicity was the proportion of nursing home residents who were Black, Hispanic, and other.

With regards to market-level factors, Medicare Advantage (MA)/managed care market penetration was calculated as the proportion of all Medicare beneficiaries in the county who were enrolled in a MA plan. Per capita income is a measure of the average wealth of individuals in a county. Educational level was percent of individuals in a county with a high-school degree or better. Unemployment rate was the percent of individuals in the county who were unemployed. Poverty level was the percent of persons and families below poverty threshold in the county, as defined by the Office of Management and Budget's Statistical Policy Directive 14. 
Table 2 Electronic Health Record Questionnaire

Administrative functions

A. Minimum Data Set Assessment/Resident Assessment Protocol/Care Area Assessments

- Paper only (no automation)

- Paper and electronic

- Fully electronic

- Not available/not applicable

B. Assessments other than Minimum Data Set

- Paper only (no automation)

- Paper and electronic

- Fully electronic

- Not available/not applicable

C. Financial management

- Paper only (no automation)

- Paper and electronic

- Fully electronic

- Not available/not applicable

D. Quality improvement and reporting

- Paper only (no automation)

- Paper and electronic

- Fully electronic

- Not available/not applicable

E. Patient care planning

- Paper only (no automation)

- Paper and electronic

- Fully electronic

- Not available/not applicable

F. Task list (e.g., CNA workflow)

- Paper only (no automation)

- Paper and electronic

- Fully electronic

- Not available/not applicable

Documentation

G. Patient demographics

- Paper only (no automation)

- Paper and electronic

Table 2 (continued)
Table 2 (continued)

- Fully electronic

- Not available/not applicable

H. Advance directives

- Paper only (no automation)

- Paper and electronic

- Fully electronic

- Not available/not applicable

I. Medical history

- Paper only (no automation)

- Paper and electronic

- Fully electronic

- Not available/not applicable

J. Clinical notes

- Paper only (no automation)

- Paper and electronic

- Fully electronic

- Not available/not applicable

K. Problem list

- Paper only (no automation)

- Paper and electronic

- Fully electronic

- Not available/not applicable

L. Allergy list

- Paper only (no automation)

- Paper and electronic

- Fully electronic

- Not available/not applicable

M. Medication administration record

- Paper only (no automation)

- Paper and electronic

- Fully electronic

- Not available/not applicable

N. Treatment administration record

- Paper only (no automation)

- Paper and electronic

- Fully electronic

- Not available/not applicable

Table 2 (continued) 
Table 2 (continued)

O. Summary reports including transfer, discharge, and consults

- Paper only (no automation)

- Paper and electronic

- Fully electronic

- Not available/not applicable

Order entry

P. Medication order entry

- Paper only (no automation)

- Paper and electronic

- Fully electronic

- Not available/not applicable

Q. Other order entry

- Paper only (no automation)

- Paper and electronic

- Fully electronic

- Not available/not applicable

Results Viewing

R. Labs

- Paper only (no automation)

- Paper and electronic

- Fully electronic

- Not available/not applicable

S. Radiology

- Paper only (no automation)

- Paper and electronic

- Fully electronic

- Not available/not applicable

T. Other diagnostic tests

- Paper only (no automation)

- Paper and electronic

- Fully electronic

- Not available/not applicable

U. Consults

- Paper only (no automation)

- Paper and electronic

- Fully electronic

Table 2 (continued)
Table 2 (continued)

- Not available/not applicable

- Clinical tools

V. Clinical decision support

- Paper only (no automation)

- Paper and electronic

- Fully electronic

- Not available/not applicable

W. Telemonitoring/telehealth

- Paper only (no automation)

- Paper and electronic

- Fully electronic

- Not available/not applicable

For each function listed below, please indicate the level of automation (or computerization) currently in use at your facility.

Competition was conceptualized using the HHI, which is measured as the sum of the squared of the market shares (based on beds) for nursing homes in a county. HHI is a continuous variable that ranges from 0 to 1 with lower values associated with higher competition-a HHI score close to zero would represent perfect competition. The location variable was included to capture the difference as it related to different markets. It had urban and rural categories where the urban was the reference category. Number of individuals over the age of 65 was the proportion of all individuals who were 65 and older to the total population.

\section{Analysis}

To adjust for potential non-response bias of nursing homes not participating in the survey, we included propensity score weights in the regression analysis (26). The propensity score weights were calculated as the inverse of the propensity scores for nursing homes that participated in the survey. To estimate the propensity score, we used a logistic regression model where we regressed respondence status (respondent $=1$, non-respondent $=0$ ) on the control variables: size, ownership status, chain affiliation, payer mix, acuity index, occupancy rate, race/ethnicity, registered nurse staffing mix, registered nurse hours per resident day, licensed practical nurse hours per resident day, certified nursing assistant hours per resident day, Medicare MCO market penetration, per capita income, poverty, unemployment, education, 
Table 3 Descriptive statistics of the nursing home sample (N=391)

\begin{tabular}{lcc}
\hline Variable & $\begin{array}{c}\text { Mean/ } \\
\text { frequency }\end{array}$ & $\begin{array}{c}\text { Standard } \\
\text { deviation, \% }\end{array}$
\end{tabular}

Dependent variable

Star rating

$\star *$

$\star \star$

$\star \star *$

$\star \star \star \star ~$

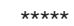
frequency deviation, \%

Independent variable

Electronic Health Record Implementation

Administrative function 1.3

Documentation

Order entry

Results viewing

Clinical tools

0.8

0.9

Organizational-level control variables

Ownership (for-profit)

For-profit

Not-for-profit

Government-run

79

$20 \%$

Chain affiliated (yes)

Yes

No

Size (number of total beds)

103.3

70.0

Occupancy rate (\%)

85.3

13.1

Payer-Mix: Medicaid (\%)

Payer-Mix: Medicare (\%)

Payer-Mix: other (\%)

Employ nurse practitioners/ physician assistants

Acuity Index (\%)

Percent of White residents (\%)

Percent of Black residents (\%)

Percent of Hispanic residents (\%)

88.3

7.2

4.7

4.4

6.9

5.7

153

$39.3 \%$

Percent of other race/ethnicity

Table 3 (continued)
Table 3 (continued)

\begin{tabular}{lcc}
\hline Variable & $\begin{array}{c}\text { Mean/ } \\
\text { frequency }\end{array}$ & $\begin{array}{c}\text { Standard } \\
\text { deviation, \% }\end{array}$ \\
\hline $\begin{array}{l}\text { County-level control variables } \\
\text { Medicare advantage penetration } \\
(\%)\end{array}$ & 29.4 & 14.9 \\
Per capita income & $\$ 43,332$ & $\$ 13,800$ \\
$\begin{array}{l}\text { Educational level (with high } \\
\text { school) }\end{array}$ & 84.6 & 6.4 \\
Unemployment rate & 5.8 & 1.8 \\
Poverty level & 17.8 & 6.5 \\
$\begin{array}{l}\text { Competition (Herfindahl- } \\
\text { Hirschman index) }\end{array}$ & 0.2 & 0.3 \\
Location (urban) & & \\
$\quad$ Urban & 369 & $94 \%$ \\
$\quad$ Rural & 22 & $6 \%$ \\
Percent of population over 65 & 15.1 & 3.3 \\
\hline
\end{tabular}

competition (HHI), location, and percent of individuals over 65. Then we calculated the inverse of the propensity score, the propensity score weight, to include in the models.

Given the ordered nature of the dependent variable (star rating), ordered logistic regression was used to model the relationship between average EHR score and quality star rating. As a sensitivity analysis, we ran a separate model where we recoded EHR score into low, medium, and high tertiles. Stata 16 was utilized for data management and analysis, and statistical tests were evaluated at the 0.05 level of significance. The study was conducted in accordance with the Declaration of Helsinki (as revised in 2013). The study was approved by the Institutional Review Board of the University of Alabama at Birmingham (IRB-140828005) and informed consent was taken from all the survey participants.

\section{Results}

The measure of internal consistency, Cronbach's alpha, among the EHR items was 0.86 (Table 1). Table 3 provides descriptive statistics of the high Medicaid nursing home whose DONs completed the survey instrument. Most of the nursing homes were for-profit and chain-affiliated. These nursing homes had $88 \%$ Medicaid and $4.7 \%$ Medicare 
payer-mix. The average occupancy was around $85 \%$. These under resourced nursing homes had a resident-mix of $19 \%$ Black, 5.3\% Hispanic, and $14.1 \%$ other non-White. They were more likely to be in urban environments with higher levels of competition.

The proportional odds model (Table 4 ) yielded a statistically significant positive relationship $(\mathrm{OR}=1.5$, $\mathrm{P}<0.05$ ) between the average EHR score and five-star quality rating, thus, our hypothesis was supported. For a one unit increase in EHR score, the odds of being in a higher star rating category would increase by $50 \%$. Sensitivity analysis (Table 5) revealed that nursing homes with high EHR implementation had higher odds of being in a higher star rating category $(\mathrm{OR}=1.75, \mathrm{P}<0.05)$, as compared with low EHR category. Additionally, not-for-profits, occupancy rate, and per capita income were significantly associated with higher quality. Specifically, nursing homes that were not-for-profit, compared to for-profit nursing homes, had higher odds $(\mathrm{OR}=2.2, \mathrm{P}<0.01)$ of being in a higher star rating category. For a one percent increase in the occupancy rate, the odds of moving to a higher star rating category increased $(\mathrm{OR}=1.0, \mathrm{P}<0.001)$. Moreover, an increase in per capita income was positively associated with a higher star rating category $(\mathrm{OR}=1.0, \mathrm{P}<0.05)$.

\section{Discussion}

Due to the growing number of aging adults, demand for long-term care services is expanding (27). For instance, there were 15,600 nursing homes serving 1.3 million residents in 2016 (28). Considering the fact that majority of those services are covered by Medicare and Medicaid, it is in the public interest to explore the strategies that can help improve the quality of care and save costs. The expanded use of technology such as EHRs in healthcare may help healthcare providers deliver higher quality services at an affordable price.

Utilizing constructs of the SPO and the knowledge-based view of the firm, the purpose of this study was to examine the relationship between EHR average scores and resident quality of care, as captured by Nursing Home Compare's Five-Star Quality Rating in high Medicaid nursing homes. In line with the findings of previous studies $(16,17)$, we found that use of EHR in high Medicaid nursing homes indeed was positively associated with improvements in quality.

EHR use has numerous benefits such as improved workflow, fewer medical errors, fewer duplicate tests, and timely access to resident data (29). Further, because of their complex chronic care needs, nursing home residents frequently transition between their homes and different care settings (30). Therefore, EHR adoption is vital in nursing homes as it may facilitate successful transitions of care (31). As such, EHR may be an important structural component of nursing home resident care, which may facilitate knowledge management and better processes of care, and may ultimately be associated with better outcomes of care, such as the nursing homes' five-star quality ratings.

Due to the cross-sectional nature of the data, the findings from this study are limited to providing associations between nursing home quality and average EHR score. Additionally, this study was focused on under-resourced nursing homes and these findings may not be applicable to the nursing home population as a whole. Nevertheless, this is the first study that examined the relationship between EHR scores and quality of care in resource-constrained High Medicaid nursing homes.

\section{Policy implications}

The HITECH Act enabled healthcare providers to access EHR incentive payments when they demonstrated meaningful use of health information technology in the forms of improved quality, safety, and effectiveness of patient care (32). While this incentive program has helped many providers adopt/upgrade health information technologies, long-term care facilities including skilled nursing facilities and assisted living homes were considered ineligible for incentives (33). Consequently, the long-term care facilities lag behind in EHR adoption (33). Still, due to promising evidence of the potential benefits of EHR use, its adoption increased from 3\% in 2010 (34) to 66 percent in 2017 (35). However, our findings complement existing research to illustrate the importance of EHR adoption in long-term care facilities. Further Federal and State policies and funding could help more nursing homes adopt EHRs, which may provide another tool to help nursing homes improve the delivery of resident care.

Nursing homes operate in a competitive and highly regulated environment, mainly due to recent federal and state regulations, changes in reimbursement policies, and quality reporting requirements (36). Particularly, high Medicaid nursing homes are struggling to remain financially viable. This study suggests that with the use of EHR, nursing homes can improve their quality of care. Investing in quality improvement initiatives has shown to 
Table 4 Ordered logistic regression of the relationship between nursing home EHR implementation and star rating (N=391)

\begin{tabular}{|c|c|c|c|c|}
\hline $\begin{array}{l}\text { Variables } \\
\text { Provider characteristics }\end{array}$ & OR & $P$ value & \multicolumn{2}{|c|}{$95 \% \mathrm{Cl}$} \\
\hline Electronic health record implementation & 1.50 & $0.039^{*}$ & 1.02 & 2.20 \\
\hline \multicolumn{5}{|l|}{ Location } \\
\hline Urban & Ref & & & \\
\hline Rural & 0.76 & 0.596 & 0.28 & 2.07 \\
\hline \multicolumn{5}{|l|}{ Chain affiliation } \\
\hline \multicolumn{5}{|l|}{ No } \\
\hline Yes & 1.05 & 0.823 & 0.69 & 1.59 \\
\hline \multicolumn{5}{|l|}{ Ownership } \\
\hline For-profit & Ref & & & \\
\hline Not-for-profit & 2.16 & $0.004^{\star \star}$ & 1.28 & 3.64 \\
\hline Government & 0.84 & 0.634 & 0.41 & 1.73 \\
\hline \multicolumn{5}{|l|}{ Employ nurse practitioners/physician assistants } \\
\hline No & Ref & & & \\
\hline Yes & 0.68 & 0.067 & 0.45 & 1.03 \\
\hline Number of total beds & 1.00 & 0.246 & 1.00 & 1.00 \\
\hline \multicolumn{5}{|l|}{ Resident characteristics } \\
\hline \multicolumn{5}{|l|}{ Payer mix } \\
\hline Other & Ref & & & \\
\hline Percent of Medicaid & 1.01 & 0.518 & 0.98 & 1.05 \\
\hline Percent of Medicare & 0.98 & 0.518 & 0.93 & 1.04 \\
\hline Acuity index & 0.97 & 0.533 & 0.90 & 1.06 \\
\hline Occupancy rate & 1.03 & $0.000^{\star \star \star}$ & 1.02 & 1.05 \\
\hline \multicolumn{5}{|l|}{ Race/ethnicity } \\
\hline White & Ref & & & \\
\hline Black & 0.99 & 0.329 & 0.98 & 1.01 \\
\hline Hispanic & 1.01 & 0.450 & 0.99 & 1.02 \\
\hline Other race/ethnicity & 1.00 & 0.516 & 0.99 & 1.01 \\
\hline \multicolumn{5}{|l|}{ Community characteristics } \\
\hline Medicare advantage penetration rate & 1.00 & 0.964 & 1.00 & 1.02 \\
\hline Per capita income & 1.00 & $0.032^{*}$ & 1.00 & 1.00 \\
\hline Poverty level & 1.04 & 0.180 & 0.98 & 1.10 \\
\hline Unemployment rate & 0.87 & 0.069 & 0.75 & 1.01 \\
\hline Education (with high school diploma) & 0.98 & 0.419 & 0.93 & 1.03 \\
\hline$\%$ of people over 65 & 1.04 & 0.362 & 0.96 & 1.12 \\
\hline Competition (Herfindahl-Hirschman index) & 1.75 & 0.272 & 0.65 & 4.72 \\
\hline
\end{tabular}

${ }^{*}, \mathrm{P}<0.05,{ }^{* *}, \mathrm{P}<0.01,{ }^{* \star *}, \mathrm{P}<0.001$. 
Table 5 Sensitivity analysis

\begin{tabular}{|c|c|c|c|c|}
\hline Variables & OR & $P$ value & \multicolumn{2}{|c|}{$95 \% \mathrm{Cl}$} \\
\hline \multicolumn{5}{|l|}{ Provider characteristics } \\
\hline \multicolumn{5}{|l|}{ EHR implementation } \\
\hline Low & Ref & & & \\
\hline Medium & 1.22 & 0.418 & 0.75 & 1.99 \\
\hline High & 1.75 & 0.026 & 1.07 & 2.86 \\
\hline \multicolumn{5}{|l|}{ Location } \\
\hline Urban & Ref & & & \\
\hline Rural & 0.72 & 0.515 & 0.27 & 1.94 \\
\hline \multicolumn{5}{|l|}{ Chain affiliation } \\
\hline \multicolumn{5}{|l|}{ No } \\
\hline Yes & 1.04 & 0.868 & 0.68 & 1.57 \\
\hline \multicolumn{5}{|l|}{ Ownership } \\
\hline For-profit & Ref & & & \\
\hline Not-for-profit & 2.11 & 0.005 & 1.25 & 3.55 \\
\hline Government & 0.85 & 0.665 & 0.41 & 1.76 \\
\hline \multicolumn{5}{|l|}{ Employ nurse practitioners/physician assistants } \\
\hline No & Ref & & & \\
\hline Yes & 0.69 & 0.068 & 0.46 & 1.03 \\
\hline Number of total beds & 1.00 & 0.233 & 1.00 & 1.00 \\
\hline \multicolumn{5}{|l|}{ Resident characteristics } \\
\hline \multicolumn{5}{|l|}{ Payer mix } \\
\hline Other & Ref & & & \\
\hline Percent of Medicaid & 1.01 & 0.539 & 0.98 & 1.05 \\
\hline Percent of Medicare & 0.98 & 0.477 & 0.92 & 1.04 \\
\hline Acuity index & 0.98 & 0.583 & 0.90 & 1.06 \\
\hline Occupancy rate & 1.03 & 0.000 & 1.02 & 1.05 \\
\hline \multicolumn{5}{|l|}{ Race/ethnicity } \\
\hline White & Ref & & & \\
\hline Black & 1.00 & 0.388 & 0.98 & 1.01 \\
\hline Hispanic & 1.01 & 0.424 & 0.99 & 1.02 \\
\hline Other race/ethnicity & 1.00 & 0.426 & 1.00 & 1.01 \\
\hline \multicolumn{5}{|l|}{ Community characteristics } \\
\hline Medicare advantage penetration rate & 1.00 & 0.983 & 0.98 & 1.02 \\
\hline Per capita income & 1.00 & 0.029 & 1.00 & 1.00 \\
\hline Poverty level & 1.03 & 0.252 & 0.98 & 1.09 \\
\hline Unemployment rate & 0.87 & 0.069 & 0.76 & 1.01 \\
\hline Education (with high school diploma) & 0.98 & 0.350 & 0.93 & 1.03 \\
\hline$\%$ of people over 65 & 1.04 & 0.359 & 0.96 & 1.12 \\
\hline Competition (Herfindahl-Hirschman index) & 1.86 & 0.216 & 0.70 & 4.99 \\
\hline
\end{tabular}


lead to better financial performance $(37,38)$. EHRs may provide high-Medicaid nursing homes additional benefits that address quality and financial concerns in resource constrained environments. Further research needs to be conducted on the financial impact that EHRs could provide to these under-resourced nursing homes. Nursing home administrators may need to take into account these benefits and realize that EHRs may represent a business cases to improve the quality of care (38).

\section{Conclusions}

This finding supports the promising role of EHR in improving quality of care among nursing homes. Even though there may be barriers to the adoption and use of EHR systems in nursing homes that operate in resourceconstrained areas, there are tangible benefits that can arise from the use of EHRs. This paper illustrated how EHRs may help under-resourced nursing homes improve the quality of care. Providers and policy makers will need to consider strategies that ensure EHR adoption is promoted across a wider distribution of all nursing homes.

\section{Acknowledgments}

Funding: Agency for Healthcare Research and Quality (1R01HS023345-01).

\section{Footnote}

Provenance and Peer Review: This article was commissioned by the Guest Editors (Naleef Fareed, Ann Scheck McAlearney, and Susan D Moffatt-Bruce) for the series "Innovations and Practices that Influence Patient-Centered Health Care Delivery" published in fournal of Hospital Management and Health Policy. The article has undergone external peer review.

Reporting Checklist: The authors have completed the SURGE reporting checklist. Available at http://dx.doi. org/10.21037/jhmhp-20-64

Data Sharing Statement: Available at http://dx.doi. org/10.21037/jhmhp-20-64

Conflict of Interest: All authors have completed the ICMJE uniform disclosure form (available at http://dx.doi. org/10.21037/jhmhp-20-64). The series "Innovations and
Practices that Influence Patient-Centered Health Care Delivery" was commissioned by the editorial office without any funding or sponsorship. Robert Weech-Maldonado serves as an unpaid editorial board member of fournal of Hospital Management and Health Policy from September 2018 to August 2020. Dr. GD reports grants from Agency for Healthcare Research and Quality (1R01HS023345-01), during the conduct of the study. Dr. JL reports grants from Agency for Healthcare Research and Quality (1R01HS023345-01), during the conduct of the study. Dr. AG reports grants from Agency for Healthcare Research and Quality (1R01HS023345-01), during the conduct of the study. Dr. RWM reports grants from Agency for Healthcare Research and Quality (1R01HS023345-01), during the conduct of the study. The authors have no other conflicts of interest to declare.

Ethical Statement: The authors are accountable for all aspects of the work in ensuring that questions related to the accuracy or integrity of any part of the work are appropriately investigated and resolved. The study was conducted in accordance with the Declaration of Helsinki (as revised in 2013). The study was approved by the Institutional Review Board of the University of Alabama at Birmingham (IRB-140828005) and informed consent was taken from all survey participants.

Open Access Statement: This is an Open Access article distributed in accordance with the Creative Commons Attribution-NonCommercial-NoDerivs 4.0 International License (CC BY-NC-ND 4.0), which permits the noncommercial replication and distribution of the article with the strict proviso that no changes or edits are made and the original work is properly cited (including links to both the formal publication through the relevant DOI and the license). See: https://creativecommons.org/licenses/by-nc-nd/4.0/.

\section{References}

1. Mather M, Jacobsen L, Pollard K. Aging in the United States. Population Bulletin. Available online: https:// www.prb.org/wp-content/uploads/2016/01/aging-uspopulation-bulletin-1.pdf

2. Stucki G, Bickenbach J, Gutenbrunner C, et al. Rehabilitation: The health strategy of the 21 st century. J Rehabil Med 2018;50:309-16.

3. Mor V, Zinn J, Angelelli J, et al. Driven to tiers: socioeconomic and racial disparities in the quality of 
nursing home care. Milbank Q 2004;82:227-56.

4. Hitt LM, Tambe P. Health care information technology, work organization, and nursing home performance. Ilr Review 2016;69:834-59.

5. Cheevakasemsook A, Chapman Y, Francis K, et al. The study of nursing documentation complexities. Int J Nurs Pract 2006;12:366-74.

6. O'Connell B, Myers H, Twigg D, et al. Documenting and communicating patient care: Are nursing care plans redundant? Int J Nurs Pract 2000;6:276-80.

7. HealthIt. Benefits of HER. 2017: Available online: https:// www.healthit.gov/topic/health-it-basics/benefits-ehrs

8. Tang P. Key capabilities of an electronic health record system. Washington, DC: Institute of Medicine of the National Academies, 2003.

9. Adler-Milstein J, Jha AK. HITECH Act Drove Large Gains In Hospital Electronic Health Record Adoption. Health Aff (Millwood) 2017;36:1416-22.

10. Alvarado CS, Zook K, Henry J. Electronic health record adoption and interoperability among US skilled nursing facilities in 2016. Available online: https://www.healthit. gov/sites/default/files/electronic-health-record-adoptionand-interoperability-among-u.s.-skilled-nursing-facilitiesin-2016.pdf

11. Vest JR, Jung HY, Wiley K Jr, et al. Adoption of Health Information Technology Among US Nursing Facilities. J Am Med Dir Assoc 2019;20:995-1000.e4.

12. Adler-Milstein J, Holmgren AJ, Kralovec P, et al. Electronic health record adoption in US hospitals: the emergence of a digital "advanced use" divide. J Am Med Inform Assoc 2017;24:1142-8.

13. The Office of the National Coordinator for Health Information Technology. Office-based physician electronic health record adoption, Health IT Quick-Stat\# 50. 2019: Available online: https://dashboard.healthit.gov/quickstats/ pages/physician-ehr-adoption-trends.php

14. Cherry B, Carter M, Owen D, et al. Factors affecting electronic health record adoption in long-term care facilities. J Healthc Qual 2008;30:37-47.

15. Wang T, Biedermann S. Adoption and utilization of electronic health record systems by long-term care facilities in Texas. Perspect Health Inf Manag 2012;9:1g.

16. Kruse CS, Mileski M, Vijaykumar AG, et al. Impact of Electronic Health Records on Long-Term Care Facilities: Systematic Review. JMIR Med Inform 2017;5:e35.

17. Meehan R. Electronic Health Records in Long-Term Care: Staff Perspectives. J Appl Gerontol 2017;36:1175-96.

18. Donabedian A. Evaluating the quality of medical care.
Milbank Mem Fund Q 1966;44:Suppl:166-206.

19. Ford EW, Menachemi N, Peterson LT, et al. Resistance is futile: but it is slowing the pace of EHR adoption nonetheless. J Am Med Inform Assoc 2009;16:274-81.

20. Eisenhardt KM, Santos FM. Knowledge-based view: A new theory of strategy. Handbook of Strategy and Management 2002;1:139-64.

21. Bennett R, Gabriel H. Organisational factors and knowledge management within large marketing departments: an empirical study. Available online: https://www.emerald.com/insight/content/ doi/10.1108/13673279910288707/full/html

22. Nonaka I. A dynamic theory of organizational knowledge creation. Organization Science 1994;5:14-37.

23. Darroch J. Developing a measure of knowledge management behaviors and practices. Available online: https://www.emerald.com/insight/content/ doi/10.1108/13673270310505377/full/html

24. Orzano AJ, McInerney CR, Tallia AF, et al. Family medicine practice performance and knowledge management. Health Care Manage Rev 2008;33:21-8.

25. Abramson EL, McGinnis S, Moore J, et al. A statewide assessment of electronic health record adoption and health information exchange among nursing homes. Health Serv Res 2014;49:361-72.

26. Austin PC. An Introduction to Propensity Score Methods for Reducing the Effects of Confounding in Observational Studies. Multivariate Behav Res 2011;46:399-424.

27. Robison J, Shugrue N, Fortinsky RH, et al. Long-term supports and services planning for the future: implications from a statewide survey of Baby Boomers and older adults. Gerontologist 2014;54:297-313.

28. Harris-Kojetin LD, Sengupta M, Lendon JP, et al. Longterm care providers and services users in the United States, 2015-2016. Available online: https://www.cdc.gov/nchs/ data/series/sr_03/sr03_43-508.pdf

29. Lieber HS. As Electronic Health Record Implementations Rise... So Will Disputes. Dispute Resolution Journal. 2011;66:46.

30. The Office of the National Coordinator for Health Information Technology. 2018. Available online: https:// www.healthit.gov/resource/care-coordination-tooltransition-long-term-and-post-acute-care

31. Burke RE, Juarez-Colunga E, Levy C, et al. Rise of postacute care facilities as a discharge destination of US hospitalizations. JAMA Intern Med 2015;175:295-6.

32. Buntin MB, Burke MF, Hoaglin MC, et al. The benefits of health information technology: a review of the recent 
literature shows predominantly positive results. Health Aff (Millwood) 2011;30:464-71.

33. Kruse CS, Mileski M, Alaytsev V, et al. Adoption factors associated with electronic health record among longterm care facilities: a systematic review. BMJ Open 2015;5:e006615.

34. Holup AA, Dobbs D, Meng H, et al. Facility characteristics associated with the use of electronic health records in residential care facilities. J Am Med Inform Assoc 2013;20:787-91.

35. Henry J, Pylypchuk Y, Patel V. Electronic Health Record Adoption and Interoperability among US Skilled Nursing Facilities and Home Health Agencies in 2017. Available online: https://www.healthit.gov/sites/default/files/ page/2018-11/Electronic-Health-Record-Adoption-and-

doi: 10.21037/jhmhp-20-64

Cite this article as: Davlyatov G, Lord J, Ghiasi A, WeechMaldonado R. Association between electronic health record use and quality of care in high Medicaid nursing homes. J Hosp Manag Health Policy 2021;5:24.
Interoperability-among-U.S.-Skilled-Nursing-Facilitiesand-Home-Health-Agencies-in-2017.pdf

36. Lord J, Davlyatov G, Thomas KS, et al. The Role of Assisted Living Capacity on Nursing Home Financial Performance. Inquiry 2018;55:46958018793285.

37. Weech-Maldonado R, Neff G, Mor V. Does quality of care lead to better financial performance?: the case of the nursing home industry. Health Care Manage Rev 2003;28:201-16.

38. Weech-Maldonado R, Pradhan R, Dayama N, et al. Nursing home quality and financial performance: is there a business case for quality? INQUIRY: The Journal of Health Care Organization, Provision, and Financing. 2019;56:0046958018825191. 